


\section{Trübners Bibliothek}

\section{Soldatische Volkskunde:}

Nr. 4: Das deutsche Soldatenlied im Felde von John Meier. kl. $8^{\circ}$. 76 S. 1916. Geheftet M. 1.25, kartoniert M. 1.75 .

Nr. 7: Deutscher Soldatenbrauch und Soldatenglaube von Hanns Bächtold. kl. $8^{\circ}$. V, 48 S. 1917. Geheftet ca. M. 1.25, kartoniert ca. M. 1.75.

Nr. 9: Deutsche Soldatensprache von Otto MauBer. kl. 8. Ca. 10 Bogen. 1917. Geheftet ca. M. 3.50. 


$$
\text { Trübners } \underset{\text { Band } 8}{B \text { i b li o the } k}
$$

\section{VOLKSLIEDSTUDIEN}

von

John Meier

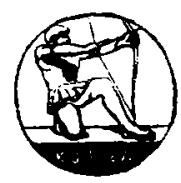

\section{StraBburg}

Verlag von Karl J. Trübner

1917

(.S) 
Alle Rechte rorbehalten

C. A.Wagners Hof- und Universitätshuchdruckerel, Freiburg in Breisgau. 


\section{MEINER FRAU ZU EIGEN}


Es ist mit Neinungen, die man wagt, wie mit Steinen, die man voran im Brette bewegt; sie können geschlagen werden, aber sio haben ein Spiel eingelcitet, das gewonnen wird.

J. W. Goethe, Spriiche in Prosn. 